\title{
EDITORIAL
}

\section{Organic Agriculture: A sustainable, eco-friendly system of crop production}

Organic agriculture (OA) is a production system that takes into account the entire ecosystem of crop cultivation including the health of the soils and of the people that consumes its products. It has a holistic approach to protect the ecosystem on a long term perspective based upon four principals: health, ecology, fairness and care. It relies upon processes of ecology, biodiversity and natural cycles often mediated by indigenous living microorganisms (both flora and fauna). Sustainable agriculture which can be considered as a partner of OA, integrates the disciplines of food security, nutrient cycling, water quality and supply, soil health, energy efficiency, pest control, breeding, animal and plant physiology, ecology and the economics of production. Sustainable agriculture employs ecological principles and use environmentally friendly, renewable strategies in agriculture to protect biodiversity. New ecofriendly solutions have been developed based on findings from various fields of science including botany, agronomy, ecology, microbiology, food nutrition and entomological sciences. OA is a management system that avoids the use of inorganic fertilizers, synthetic pesticides and genetically modified organisms (GMOs) and that seeks to reduce pollution of air, soil, and water and optimize the health and productivity of interdependent communities of plants, animals and humans.

On the contrary, the use of synthetic chemical fertilizers and other agro-chemicals together with newly bred high input responsive crop cultivars was introduced under the "Green Revolution" some 60 to 65 years back. This was introduced after the World War II primarily to overcome mass starvation. It also provided markets to an industry based upon fossil fuel refinery by-products owned at that time by the war victorious powerful nations. These inorganic chemicals were added to soils that had plenty of organic matter accumulated over several centuries of OA. The soluble chemical nutrients were retained in the organically rich soils to be effectively absorbed by crop plants producing dramatic increases in yield. Arguably it contributed to prevent global starvation at that time. This novel system became overwhelmingly popular and spread throughout the world. Today it is accepted as conventional agriculture and had become a massive industry reducing OA to less than $10 \%$ of global agriculture. This system produces short-term benefits to farmers but results in the degradation of overall soil fertility over time, makes the plants more susceptible to pest and pathogens, increases weed growth, kills soil microorganisms and disorients and misleads the farming communities who become addicted to the system. This leads to a vicious cycle of trying to sustain crop productivity on 'dead soils' which is impossible without more and more chemical inputs. Such inactive soils with little or no organic matter and microbial activity cannot retain the soluble chemicals applied, particularly nitrogen and phosphorus. Less than $30 \%$ of the chemicals added to such soils are absorbed by the crops and $70 \%$ flows through streams, rivers, canals and end up in reservoirs, irrigation tanks and other stagnant water bodies leading to eutrophication and hypereutrophication. Eutrophication results in algal bloom formation especially by cyanobacteria (blue-green algae) a number of which produce algal toxins harmful to animals including humans. It is increasingly clear that over use and misuse of chemical fertilizers and other agro-chemicals (which are encouraged under subsidy schemes in several countries), have aggravated environmental pollution. On a global scale such pollution has led to the creation of 'dead zones' in the oceans causing international concerns and increased the incidence of environmentally related noncommunicable illnesses such Chronic Kidney Disease of uncertain etiology $(\mathrm{CKDu})$, certain cancers, heart ailments, blue baby syndrome particularly in developing countries, predominantly among the farming communities.

Due to the realization of such negative impacts, there is a global trend to return to OA. By 2019 it is reported to be practiced in 181 countries. Land devoted to OA globally had increased from 15.8 $\mathrm{Mn}$ ha to $37.2 \mathrm{Mn}$ ha during the past decade and has reached $69.8 \mathrm{Mn}$ ha in 2017. The annual global market for organic products which went up from 20.1 Bn US \$ to 81.6 Bn US \$ from 2001 to 2015 and had increased to $97 \mathrm{Bn}$ US \$ in 2017.

With radical changes to global energy use forecasted to happen during the next 10 to 20 years, it would become inevitable that conventional agriculture may have to be replaced by OA based upon natural renewable cycling systems.

\section{Revolutionary changes in global energy production and usage}

Global concerns on the pollution of air, water and soil caused due to fossil fuel burning by massive industries contributing significantly to climate change, has resulted in international organizations like the International Energy Agency (IEA), the International Panel on Climate Change (IPCC) of the UN to propose stringent reductions of fossil fuel based energy utilization. According to a report on Yahoo News of $19^{\text {th }}$ May 2021 by David Knowles (a science correspondent), agreement has been reached among all the major industrialized countries to: (a) reduce industrial methane emissions by $75 \%$ by 2030 , (b) terminate the manufacture of Internal Combustion (IC) engines and all diesel and petrol vehicles by 2035, (c) increase renewable energy production from 29 to $90 \%$ by 2050 , (d) stop the construction of new coal powered power plants by 2021 
and close down all existing coal power plants by 2040 (except those with internal carbon capture technology), (e) phasing out of oil and gas heating of buildings, (f) phasing out sales of gasoline vehicles by 2035, (g) conversion of vehicle fleets to electric or hydrogen by 2050 and (h) transitioning $50 \%$ of all air travel to hydrogen or bio-fuels by 2040 . As all the major industrialized countries including the USA, China, Russia, European Union, Japan, India and Australia had accepted these proposals, it is inevitable that fossil fuel based industries including synthetic chemical fertilizer manufacture will be reduced drastically within the next few decades. In this scenario the world will have no choice but to return to OA for food production.

\section{The Sri Lankan scenario}

According to the records of the Department of Census and Statistics of Sri Lanka, at the time of the introduction of chemical fertilizers to the country in the 1960/61 Maha season the national paddy yield had been around $1560 \mathrm{~kg} /$ ha. This has increased dramatically (as the chemicals were added to organically enriched soils), to $3600 \mathrm{~kg} / \mathrm{ha}$ until Maha 88/89 and then started to level off to reach $3800 \mathrm{~kg} / \mathrm{ha}$ by Maha 2004/05 and for the past five years had remained around $4200 \mathrm{~kg} / \mathrm{ha}$. This is because chemical fertilizers added continuously had reduced the organic matter and destroyed microbial activities and saturated the yield capacity of these inactive soils. Soils under continuous chemical loading had also lost their capacity to retain the added fertilizer. A large part of the chemicals find their way through streams, rivers and canals to stagnant water bodies like reservoirs and irrigation tanks leading eutrophication and toxic algal bloom formation. There had been an overall increase in environmentally related illnesses in Sri Lanka particularly among the farming communities.

These are the reasons for the pronouncement by the government to ban the importation of chemical fertilizers and agro-chemicals to Sri Lanka. All the knowledge, experience and the available resources in Sri Lanka have to be utilized with utmost commitment and based upon scientific findings, develop technologies and microbial and other non-chemical products to meet this challenge. If all these resources and energies can be mobilized with a genuine, benevolent motivation, it is possible to surmount the challenges and achieve the objective of reverting to OA as an eco-friendly, sustainable system to provide safe and healthy food to the people.

S. A. Kulasooriya National Institute of Fundamental Studies Email: ananda.ku@nifs.ac.lk 